\title{
VIRANDO O JOGO: O ESTUDO DO GÊNERO VIDEOGAME NA ESCOLA
}

\author{
Dra. Ana Paula Pinheiro da Silveira (UNOPAR / ana1@ unopar.br) \\ Dr. Anderson Teixeira Rolim (UNOPAR / anderson.rolim@unopar.br)
}

\begin{abstract}
Resumo: Esta pesquisa qualitativa interventiva, desenvolvida em uma escola pública da cidade de Londrina, investiga os letramentos necessários para a construção dos sentidos do texto Dante's Inferno, enquadrado no gênero "videogame". Seu desenvolvimento teórico parte de reflexões sobre o conceito de ludoletramento, compreendendo o jogo como um objeto que se desloca de uma situação de relativo desprestígio a uma ascensão, alçado à categoria de produto cultural, que o possibilita ser um "texto" analisado na escola e que requer habilidades. Os resultados deste trabalho apontam a viabilidade de uma proposta para o uso de videogames como estratégia para propiciar o gosto pela leitura e, também, pela literatura.
\end{abstract}

Palavras-chave: Videogame. Leitura. Ensino.

\section{TURNING THINGS AROUND: THE STUDY OF VIDEOGAME AS TEXTUAL GENRE IN SCHOOL}

\begin{abstract}
In this paper, the authors present the results of a Qualitative and Interventional research, developed in a public school in the city of Londrina. The work investigates the literacies required for the construction of meanings in Dante's Inferno, a text embedded as game textual genre. Its theoretical development starts with reflections on the concept of ludoliteracy, understanding the game as an object that historically moves itself from a situation of low to high prestige, raised to the category of cultural product, which enables it to be a "text" subject to be analyzed in class and that requires specific skills. The result of this study shows the feasibility of a proposal for the use of video games as a strategy to propitiate the students the ways to enjoy reading activities and also literature itself.
\end{abstract}

Keywords: Videogame. Reading. Teaching.

\section{Introdução}

O relatório da pesquisa Retratos da Leitura no Brasil - $3^{\text {a }}$ Edição, em 2011, indica um decréscimo no número de livros lidos pelos leitores acima de 15 anos, se comparados à mesma população, na pesquisa realizada em 2007. Em contrapartida, três livros inspirados em Assassin's Creed, jogo adaptado para livro, posicionam as adaptações literárias da série entre as mais vendidas, em 2011 e 2012: Renascença (Veja, 12/10/2011, p. 169), Irmandade (Veja, 02/05/2012, p. 141) e A Cruzada Secreta (Veja, 15/08/2012, p. 133).

Partindo, portanto, dos resultados da pesquisa Retratos da Leitura no Brasil - $3^{\text {a }}$ Edição (2011) e daqueles apontados pela revista Veja sobre a adaptação do videogame Assassin's Creed (Veja, 12/10/2011; 02/05/2012; 15/08/2012), que possibilitam intuir a relação entre videogames e mercado editorial, delineamos o objeto de pesquisa tecnologia e leitura -, e isso poderia ser concretizado por meio da análise da leitura de um jogo. 
Algumas objeções, no entanto, interpuseram-se na escolha, como, por exemplo, a ideia de que ainda havia certo desconforto na academia e, consequentemente, na escola em relação ao trabalho didático com videogames. Conforme elucidado por Herschmann (2012, p. 303-304), “o boom dos games eletrônicos é encarado de forma preconceituosa e negativa: como um claro sinal de um processo de 'infantilização do social', resultado de um empobrecimento cultural".

Corrobora a argumentação de Herschmann (2012) o recente episódio com a Ministra da Cultura, Marta Suplicy, durante a apresentação do projeto Vale-Cultura, no dia 19 de fevereiro de 2013, em que ela justificou: "eu não acho que jogos digitais sejam cultura" (Locatelli, 2013).

Uma possibilidade de resolver o preconceito da academia e da escola era trabalhar um jogo inspirado em um texto literário. Nesse sentido, o jogo Dante's Inferno trazia uma relação estreita com a cultura: inspirado em A Divina Comédia, uma obra literária do século XIV. Ademais, havia já pesquisadores que vislumbram o trabalho com videogames como uma experiência importante e atual para o ensino, como elucidam Sá e Andrade (2008, p. 12): "Jogos são ambientes para o aprendizado de competências cognitivas, tornando-se, cada vez mais, a experiência pedagógica por excelência da atualidade; e o lúdico é um elemento fundamental da comunicação contemporânea em todas as esferas".

Uma pesquisa que elegesse como objeto de estudo a utilização de videogames no ensino da leitura não poderia, na tentativa de defender o seu valor educacional, conforme elucidado por Sá e Andrade (2008), assumir uma posição ingênua e acrítica, como se a resolução para o problema da leitura e da sedução do leitor se findasse com o uso desses jogos em sala de aula. Teria de analisar como os alunos constroem sentidos para esses textos, se o fazem de modo reflexivo, se são capazes de perceber os mecanismos manipuladores presentes nos videogames e se a atividade de leitura envolve percepção, processamento, dedução, inferências na construção dos sentidos do texto. Para isso, estabelecemos as seguintes perguntas com o objetivo de nortear este estudo:

1. Jogar videogame requer uma habilidade ou um letramento específico?

2. Como esses letramentos cooperam para a construção dos sentidos do texto?

Como essas perguntas orientam-nos a investigar as habilidades de letramentos, fez-se necessário analisar como os autores situam o videogame nos estudos do letramento.

\section{O videogame: um gênero multimodal}

O domínio da língua, na perspectiva dos Parâmetros Curriculares Nacionais (PCN), tem estreita relação com a possibilidade de plena participação social, haja vista que é por meio dela que o homem "partilha ou constrói visões de mundo, produz conhecimentos" (Brasil, 1997). Nesse sentido, o documento do MEC sugere que o ensino seja pautado em práticas de ensino que possibilitem ao aluno aprender a linguagem a partir da diversidade de textos que circulam socialmente, ou seja, indica uma proposta com gêneros do discurso, "fenômenos históricos, profundamente vinculados à vida cultural e social", conforme salienta Marcuschi (2003, p. 19).

Santaella (2009) classifica o videogame como um gênero híbrido, argumentando que absorve a linguagem de outras mídias e envolve uma soma de elementos na sua produção, como roteiro, navegação, programação e usabilidade; um 
gênero multimodal, que envolve na sua produção e recepção diferentes semioses e define-se pela presença de suporte eletrônico e de algumas características, como o algoritmo, a ludicidade, a interatividade e a imersividade, estreitamente relacionadas, uma vez que, "sem o agenciamento participativo do jogador e sem o prazer quase mágico que é próprio das atividades lúdicas, não haveria jogo" (Santaella, 2009, p. xiii).

Não pretendemos, neste trabalho, tecer aprofundamentos sobre a teoria dos gêneros discursivos, mas discutir e apontar alguns caminhos para a leitura do videogame, compreendendo, como elucidou Gee (2003), que cada gênero presente na esfera social possui um modo determinado cultural e historicamente de leitura e escrita e, logo, exige também letramentos específicos para a sua produção e recepção. No caso do videogame, tem de estar inserido em um contexto de domínio semiótico, o que requer algumas habilidades, como: a) a decodificação; b) a compreensão dos significados de cada domínio semiótico; c) a produção de significados em cada domínio semiótico.

A partir das discussões de Gee (2003), Zagal (2010) aprofundou o conceito de ludoletramento, termo específico para a análise da leitura de videogames, que aprofundaremos na próxima seção.

\section{Ludoletramento: de que conceito estamos falando?}

Muitos foram os estudos, na última década, que se debruçaram sobre os videogames. Segundo Zagal (2010), as diferentes tendências de análise impulsionaram um aprofundamento não só multidisciplinar mas também interdisciplinar, com abordagens que se orientaram para: a) as ciências sociais - os efeitos dos jogos sobre os jogadores e as relações entre jogos e aprendizagem; b) as ciências humanas - o significado dos jogos na sociedade e sua relação com a cultura; c) as ciências tecnológicas - com o objetivo de compreender o design dos jogos e para produzi-los com novos recursos tecnológicos, incluindo, nessa etapa das discussões, o ponto de vista narratológico e ludológico.

Com o reconhecimento dos jogos eletrônicos como produto cultural, como "arte na mídia", novas pesquisas encontram modos diferentes de olhar para esse objeto. Pouco, porém, encontramos produzido sobre as relações entre videogame e letramento. Os primeiros trabalhos nessa área são de Gee (2003). Na sua obra What videogames have to teach us about learning and literacy, apresenta razões para relacionar os videogames aos estudos do letramento, argumentando que os videogames são produzidos valendo-se de imagens, símbolos, gráficos, diagramas, artefatos e muitos outros símbolos visuais, ou seja, de modo multimodal, o que justificaria a necessidade de um letramento visual para poder compreender como a linguagem verbal e a não verbal articulam-se para construir sentidos para o texto.

Compreender os videogames a partir desse viés teórico implica não só considerar o seu caráter multimodal mas também outros aspectos a ele imbricados, como as práticas sociais em que estão inseridos e a multiculturalidade. Sobre esse primeiro argumento, Zagal (2010), analisando as justificativas de Gee (2003) e as habilidades de letramento consideradas por ele para um leitor/jogador, ou seja, a habilidade de jogar, a habilidade de compreender os significados imanentes ao sistema semiótico do jogo e a habilidade de produzir jogos, afirma que estabelecer as interrelações entre tais habilidades pode não ser tão simples. Sua justificativa está amparada no ato de jogar que não se finda no reconhecimento das regras do jogo e da sua interface, mas na capacidade do jogador trilhar um caminho, fazendo algumas escolhas, e não outras. Isso extrapola o domínio do sistema semiótico, porque inclui a capacidade 
de participar das práticas sociais de leitura e escrita que surgem a partir do videogame. $\mathrm{O}$ autor esclarece que jogar Massive Multiplayer On-line Game (MMOG) inclui a capacidade de inserir-se nas práticas sociais do jogo, e isso exige conhecer a linguagem utilizada pelos jogadores naquele contexto específico.

Zagal (2010) ainda registra, com precisão, que a capacidade de produzir jogos será um conhecimento requerido para aqueles que atuam nessa área específica, por exemplo, para os alunos do curso de designer, de jogos eletrônicos. Ele cunha um termo novo, o "ludoletramento", definindo-o como a habilidade para ler/compreender os jogos:

[...] a capacidade de explicar, discutir, descrever, enquadrar, situar, interpretar e/ou posicionar os jogos nos seguintes contextos: 1 . no contexto da cultura humana (jogos como artefatos culturais); 2. no contexto de outros jogos (comparando-os a outros jogos, gêneros); 3. no contexto da plataforma tecnológica em que são executados; 4. e na desconstrução e compreensão de seus componentes, como eles interagem, e como facilitam certa experiências em seus jogadores ${ }^{1}$ (Zagal, 2010, p. 24, grifos do autor, tradução nossa).

Visto sob esse enfoque teórico do letramento, Zagal (2010) resume a relação cultural em três aspectos: com outras mídias; com outros modos de comunicação e interação; com movimentos artísticos e outras expressões culturais.

É inegável a relação dos videogames com outras mídias. A adaptação de filmes a partir de videogames e de videogames a partir de filmes não é um dado recente. Respeitados os limites de cada mídia, a adaptação pode privilegiar a representação de um meio em outro, por exemplo, um videogame em um filme, ou pode acontecer de modo complementar, em que o jogo oportuniza uma nova experiência de entretenimento a partir do universo ficcional do filme, porém, embora seja possível jogar o jogo de forma autossuficiente, a sua compreensão plena depende da história que se passa no filme.

Em relação aos movimentos artísticos, os jogos compartilham a estética, a temática - Dante's Inferno é um exemplo - e elementos estruturais presentes em movimentos da Arte.

Uma preocupação dos estudiosos do multiletramento é compreender como a escola agrega os valores trazidos pela diversidade cultural, presente na cultura popular, ou aquela específica de um grupo social. Na visão de Zagal (2010), os videogames também incluem a estética, a linguagem e a música dos diferentes grupos. Segundo ele, insere-se, nesse contexto, a série de jogos Tony Hawk Pro Skater, que coloca em cena aspectos da cultura skatista urbana e, para construir sentidos, vai exigir do leitor/jogador o conhecimento das práticas discursivas desse grupo social, refletidas no jogo. Para criar o jogo, o designer fez uma escolha de elementos que caracterizam a cultura skatista: o tipo de música, a linguagem, os nomes das personagens, a caracterização do ambiente.

Para Zagal (2010), as habilidades de ludoletramento incluem, ainda, compreender a sua relação com outros jogos, aspectos comuns que fazem parte da estrutura composicional dos jogos eletrônicos, convenções relacionadas à sua mecânica. Inserem-se, nessa categoria, a pontuação do jogo e a caracterização da personagem com as habilidades que lhe são atribuídas.

Em relação à pontuação, os jogadores podem acumular pontos de dois modos: pela habilidade e experiência ou pela atribuição de pontos de vida. No primeiro caso, o jogador recebe uma pontuação segundo as tarefas que realiza no jogo e, quando atinge um número " $x$ ", ele é premiado, recebe uma recompensa, um número de pontos que lhe 
permite alcançar níveis mais altos ou maior habilidade no jogo. O segundo está diretamente relacionado à "saúde" da personagem, ou seja, quanto mais ela for atingida no jogo, menos pontos de vida possui, ao passo que, quanto menos for atingida, mais forte e poderosa se torna, podendo suportar maior tempo na partida. A relação desses dois aspectos é o que determina quanto tempo a personagem pode permanecer em uma fase para cumprir a performance exigida antes de ser derrotada.

Zagal (2010) considera importante, para compreender um jogo, identificar os componentes que o constituem e suas relações no funcionamento, como atuam e servem para facilitar a experiência, a performance dos jogadores, ou seja, como os diversos elementos são determinados, como estão combinados ou recombinados a outros. Se tomarmos como exemplo Dante's Inferno, o jogador, para descer ao inferno, tem de escalar uma parede, entre um ciclo e outro, encontrar uma alavanca para abrir uma porta, derrotar monstros, absolver ou condenar danados que encontra no inferno, obter itens necessários para um próximo desafio. O progresso do jogo, quase sempre, é determinado pelas conquistas desses itens; no caso de Dante's Inferno, o primeiro deles é a espada de Beatriz, e o segundo é a foice da morte, que lhe dão a competência para lutar e poder vencer os inimigos que encontrará em sua jornada.

Todos esses aspectos corresponderiam a compreender a gramática do jogo dentro de um domínio semiótico (Gee, 2003), por isso a necessidade de ensinar ao aluno um conhecimento teórico-metodológico que lhe permita ler os sentidos imanentes à narrativa de videogames.

\section{Materiais e Métodos}

A escola insere-se em um contexto social. É natural, portanto, que pesquisas concernentes a ela baseiem-se em métodos que favoreçam a compreensão da multiplicidade de sentidos inerentes ao universo cultural em que está inserida. Por isso, optamos por desenvolver uma pesquisa qualitativa de tipo participante e interventiva. Em nosso caso, pretendemos iluminar a análise dos dados emergentes a partir dos estudos do letramento, sem excluir, quando pertinentes, alguns conceitos advindos de obras e autores inseridos em outros referenciais teóricos.

A pesquisa foi realizada em uma escola estadual, de Ensino Fundamental, situada na periferia da cidade de Londrina-PR. A escolha atendeu à necessidade da escola, ao desenvolver um projeto voltado para a leitura, permeada por duas situações: o baixo índice do IDEB e o desinteresse dos alunos pela leitura. Segundo a professora da turma:

a) os resultados do IDEB $(3,1)$ indicavam a necessidade de realização de um projeto de intervenção voltado para a leitura;

b) a relativa apatia dos alunos em relação à aprendizagem, no caso específico da nossa pesquisa, nas aulas de Língua Portuguesa, poderia ser relacionada tanto às dificuldades de escrita e leitura apresentadas pelos alunos quanto ao contexto social em que estavam inseridos, com situações que resultavam em baixa autoestima e dificuldades de aprendizagem decorrentes da valorização das próprias capacidades.

Com objetivo de conferir credibilidade à pesquisa, foram utilizados como instrumentos de coleta e registro de dados entrevistas semiestruturadas; gravação em áudio e vídeo ${ }^{2}$; diário do professor; interpretação de texto escrita realizada pelos alunos.

Todo esse processo foi empreendido com os 27 alunos do $9^{\circ}$ ano, no primeiro 
semestre de 2012, durante 30 horas-aula, que se realizaram às quintas-feiras, das $7 \mathrm{~h} 30 \mathrm{~min}$ às $8 \mathrm{~h} 20 \mathrm{~min}$, e às sextas-feiras, das $8 \mathrm{~h} 20 \mathrm{~min}$ às $10 \mathrm{~h}$. Para a realização das atividades, utilizamos um console PlayStation 3, um projetor de vídeo e um computador portátil.

\section{Resultados e Discussão}

Na primeira etapa da intervenção, os alunos foram solicitados a jogar as duas primeiras fases da narrativa Dante's Inferno, e o nosso interesse estava voltado para como eles liam o texto e construíam sentidos para a leitura. Antes do início da partida, apresentamos o jogo, relacionando-o à obra de Dante Alighieri.

O momento do jogo revelou-nos uma surpresa, uma vez que imaginávamos que a presença de um PlayStation 3 na sala de aula resultaria em uma pequena "confusão". No início, houve um pouco de burburinho, mas, logo que a partida teve início, ouvia-se o comentário sobre a personagem, as armas, os poderes, o controle do jogador, os botões que deveriam ser apertados, as dicas para vencer a morte. Realmente, foi nítida a participação e o envolvimento dos alunos, e, mesmo sendo possível jogar apenas um de cada vez, todos os outros continuavam a dar as instruções.

Com a finalidade de compreender e analisar os dados que foram gerados nessa partida, e se os sujeitos do nosso estudo possuíam habilidades de letramento para construir sentidos para a leitura da narrativa digital Dante's Inferno, orientamo-nos pelas perguntas de pesquisa, já indicadas na introdução deste estudo.

Para investigar os letramentos semióticos, foi necessário, além da observação das partidas dos jogos, aplicar aos alunos um questionário, com cinco perguntas, para que pudéssemos levantar alguns dados sobre as relações entre videogames e textos, os seus objetivos no jogo e os caminhos percorridos por eles, no momento do jogo.

As duas primeiras perguntas, Gráficos 1 e 2, eram direcionadas para as crenças que os alunos tinham em relação ao videogame, se gostavam de jogar e se o faziam com frequência, até para compreendermos se eles possuíam habilidades para o jogo.

Os dados indicaram que grande parte dos alunos gosta de jogar, faz isso com frequência e considera o videogame um texto.

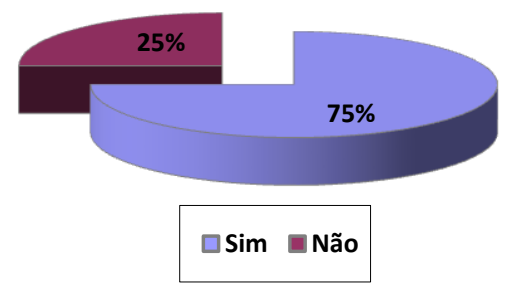

Gráfico 1 - Gosta de jogar?

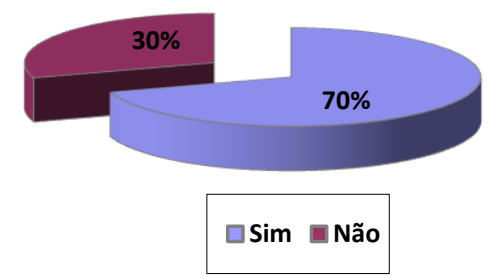

Gráfico 2 - Joga com frequência?

Os dados coletados, apresentados nos Gráficos 3, 4 e 5, permitiram-nos constatar a estreita relação do jogador com o resultado do jogo. Para o jogador, o resultado é o que irá modalizá-lo, uma vez que o desejo de vencer o jogo, de zerá-lo, torna-se o seu objeto de valor. Ele, como sujeito debreado, aceita um contrato de leitura e é modalizado pela satisfação vs. insatisfação, quando executa as tarefas que lhe permitem avançar as fases, finalizar e vencer o jogo. 


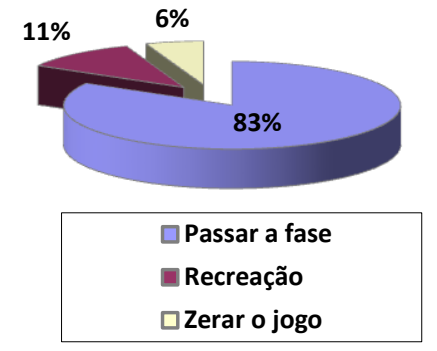

Gráfico 3 - O que, inicialmente, era o mais importante no jogo?

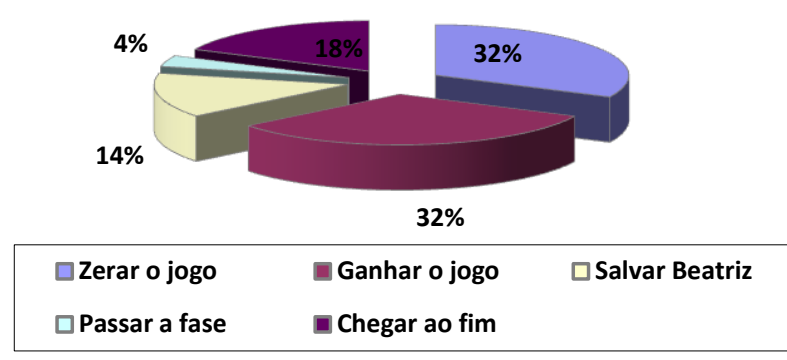

Gráfico 4 - No início do jogo, qual era o seu maior interesse?

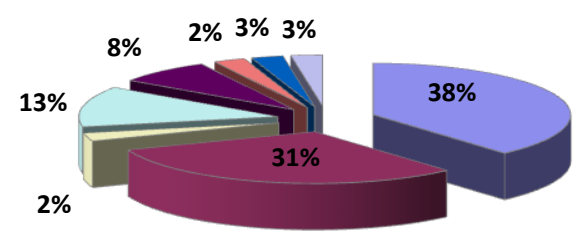

\begin{tabular}{|lll|}
\hline $\begin{array}{l}\square \text { Seguir instruções } \\
\square \text { Pistas }\end{array}$ & $\square$ Legendas & $\square$ Seguir as fases \\
$\square$ Placar & $\square$ Símbolos & $\square$ Vídeos da internet \\
\hline
\end{tabular}

Gráfico 5 - Estratégias selecionadas para passar as fases.

Em relação à prática do videogame, retomamos ainda dados apresentados nos Gráficos 1 e 2, que apontaram que 75\% dos sujeitos gostam de jogar, e $70 \%$ o fazem com frequência, o que deveria garantir que possuem habilidades de letramento requeridas para o jogo, como a decodificação, a compreensão dos significados de cada domínio semiótico e a produção de significados em cada domínio semiótico, de acordo com Gee (2003).

Para melhor organizar os dados referentes às habilidades de letramento ou de ludoletramento, como cunhou Zagal (2010), que remetem à leitura, ao uso, à compreensão e à produção de jogos, elaboramos um quadro, com o cruzamento dos dados da partida gravada e das respostas do Gráfico 5, retomando o conceito de ludoletramento e comparando-o às ações ou habilidades observadas ou elencadas pelos nossos sujeitos no momento do jogo.

Zagal (2010, p. 24, tradução nossa) conceitua o ludoletramento como "[...] a capacidade de explicar, discutir, descrever, enquadrar, situar, interpretar e/ou posicionar os jogos nos seguintes contextos":

Contextos de uso de

letramento, descritos por Zagal (2010, p. 24)

1. contexto da cultura humana (jogos como artefatos culturais)

2. contexto de outros jogos (comparando-os a outros jogos, gêneros)

\section{Recursos ou ações utilizados pelos sujeitos da pesquisa, durante a partida do jogo e/ou sua análise.}

Estabeleceram relação do game com outras mídias ou outras obras, como a adaptação do videogame para o filme $O$ Inferno de Dante, em animé, em 2010; A Divina Comédia e sua concepção de inferno, os pecados capitais e suas representações na bíblia, no discurso religioso.

Reconheceram elementos da estrutura do gênero videogame presentes em outros jogos, como as telas de abertura; de bonificação; de pontuação; de melhorias; as armas; a barra de vida. 


\begin{tabular}{|l|l|}
\hline $\begin{array}{l}\text { 3. contexto da plataforma } \\
\text { tecnológica em que são } \\
\text { executados }\end{array}$ & $\begin{array}{l}\text { Seguiram instruções dadas, quando apertaram o joypad, } \\
\text { reconhecendo os códigos } \square \text { X. } \\
\text { Acessaram as bonificaçôes disponíveis nas telas para aumento } \\
\text { de nível. } \\
\text { Salvaram o jogo. Resolveram os puzzles. Desceram a arena do } \\
\text { jogo. Abriram e fecharam portas. Utilizaram alavancas. }\end{array}$ \\
\hline $\begin{array}{l}\text { 4ealizaram tarefas para alcançar outra, como a aquisição de } \\
\text { desconstrução e } \\
\text { compreensão de seus } \\
\text { componentes. }\end{array}$ & $\begin{array}{l}\text { Controlaram o avatar, que abarcou ações como lutar, usar as } \\
\text { armas, correr, saltar, caminhar nas paredes, derrotar os } \\
\text { inimigos. }\end{array}$ \\
\hline
\end{tabular}

Quadro 1 - Comparação entre o conceito de ludoletramento (ZAGAL, 2010) e as habilidades utilizadas pelos sujeitos.

Analisando o Quadro 1 e o Gráfico 5, observamos que as estratégias utilizadas pelo leitor/jogador requerem habilidades de letramento específicas, como conhecer os significados dos símbolos (placar, pistas, barra de vida), as instruções dadas, quando se aperta o joypad, bem como as que ficam disponíveis nas telas para aumento de nível, bonificação e sanções, e que elas cooperam para a construção dos sentidos do texto. Seguindo esse caminho traçado pelo jogador, a narrativa foi colocada em segundo plano, e ela não aparece em nenhum momento, como opção de estratégia, como algo importante ou de interesse do sujeito no início do jogo. Pelo contrário, alguns saltaram a parte narrativa (cut-scenes) para poderem interagir mais rapidamente e terem a possibilidade de acelerar o final da fase.

No que concerne à leitura, vale recordar, ainda, que o fazer interpretativo do jogador extrapola o uso das habilidades de letramento, uma vez que o videogame assemelha-se, no que concerne à interpretação, a outras práticas artísticas, como a música e o teatro, que requerem do interpretante "a dimensão produtiva e performativa do fazer interpretativo" (Meneghelli, 2005), que inclui a dimensão pragmática e passional. A interpretação do jogador não se limita a uma dimensão cognitiva, conforme vimos em Gee (2003), exigindo que possua letramentos para ler o texto, mas requer também uma prática que transforma, por meio de sua ação no momento do jogo, o plano de expressão do texto. A experiência de leitura, nessa perspectiva, está estreitamente ligada à sedução provocada pelo simulacro da imersão e, por isso, a narrativa é colocada em segundo plano.

Compreender símbolos, legendas, pistas e placares, na visão de Zagal (2010) e de Gee (2003), constitui competências exigidas para o entendimento do jogo, como habilidades de letramento. Porém, somente essas habilidades não possibilitam ao sujeito construir sentidos para a narrativa. Isso pode ser comprovado por nós, quando solicitamos aos alunos que reconstruíssem a história das duas primeiras fases. Por isso, com o objetivo de aprofundar a leitura do texto, analisamos os vídeos das partidas, conforme resultados indicados no Gráfico 6, que reúne as respostas dos alunos, quando foram perguntados sobre quais fatores consideravam determinantes para entender a narrativa e para estabelecer relações intertextuais com outros textos analisados na pesquisa $^{3}$. Os vídeos e as análises das imagens totalizaram $47 \%$, o que nos permite afirmar que somente o jogo como um instrumento recreativo, como entretenimento, no caso desta pesquisa, não favorece a construção de sentidos, sendo necessária a análise de vídeos das partidas, dos conteúdos das legendas, das imagens, bem como a mediação do professor, que foi apontada por $37 \%$ dos sujeitos como um fator determinante para que pudessem perceber os sentidos imanentes no texto.

Esses dados trazem à luz a importância do papel do professor como mediador. 
Certamente, o aluno pode adquirir habilidades de ludoletramento fora da escola e de forma autônoma, mas é importante considerar que, para ler as imagens, estabelecer relações entre plano de conteúdo e de expressão, compreender que convergem para a construção de sentidos, e para que possa desenvolver o letramento crítico, há a exigência da mediação, papel importantíssimo do professor diante do uso das tecnologias no século XXI.

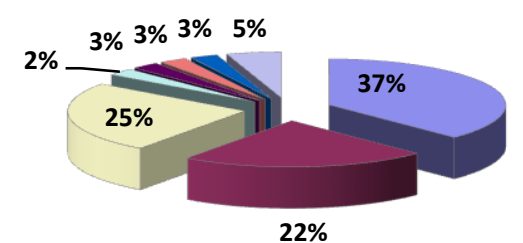

\begin{tabular}{|c|c|c|c|}
\hline $\begin{array}{l}\square \text { Explicações da professora } \\
\text { Dialogar sobre os textos }\end{array}$ & $\begin{array}{l}\text { Assistir aos vídeos } \\
\text { Ler a legenda }\end{array}$ & $\begin{array}{l}\square \text { Análise das imagens } \\
\text { As cut-scenes }\end{array}$ & $\begin{array}{l}\square \text { Seguir as instruções } \\
\square \text { Estudo }\end{array}$ \\
\hline
\end{tabular}

Gráfico 6 - Elementos determinantes para a compreensão da história.

O trabalho organizado também em um ambiente virtual foi, ao mesmo tempo, apresentando outras obras com as quais os alunos puderam estabelecer relações, e isso possibilitou que eles recorressem às fontes. Uma aluna começou a ler A Divina Comédia, enquanto os outros sujeitos interessaram-se por conhecer Supernerd - a Saga dantesca, O purgatório - a verdadeira história de Dante e Beatriz e A Divina Comédia em quadrinhos. Como sugestão da professora regente, no último encontro, fizemos um sorteio desses três livros. Na segunda-feira, apenas dois dias após a entrega dos livros, os alunos contemplados já tinham concluído a leitura, e havia uma lista de espera para adentrar no prazer que essas obras podiam oferecer.

\section{Conclusões}

Em relação ao fazer interpretativo do leitor/jogador, com base nos questionários e na observação das partidas do jogo, na sala de aula, concluímos que os sujeitos, no momento do jogo, como avatar, fizeram a experiência de um sujeito debreado, modalizado pelo querer-vencer a partida, uma vez que o resultado do jogo é fundamental para a manipulação do sujeito, é o que provoca a emoção de satisfação $v s$. insatisfação. Os sujeitos executaram as tarefas, seguindo estratégias como pistas, analisando telas de bônus, de vida, mensagens na tela, legendas que apareciam quando se apertavam os botões do joypad; serviram-se das habilidades de ludoletramento requeridas para o jogo, como a decodificação e a compreensão dos significados de cada domínio semiótico e a produção de significados em cada domínio semiótico.

Os resultados deste trabalho possibilitam viabilizar uma proposta do uso de videogames, como estratégia para que o aluno aprenda a ler e possa desenvolver o gosto pela leitura e pela literatura, além de aprofundar a importante discussão sobre as novas tecnologias como suporte para o ensino de linguagem, escrita e leitura.

\footnotetext{
${ }^{1}$ Trecho original: "[...] the ability to explain, discuss, describe, frame, situate, interpret, and/or position games: 1 . in the context of human culture (games as a cultural artifacts), 2 . in the context of other games (comparing games to other games, genres), 3. in the context of the technological platform on which they are executed, 4. and by deconstructing them and understanding their components, how they interact, and how they facilitate certain experiences in players" (ZAGAL, 2010, p. 24).

${ }^{2}$ Neste artigo são descritos somente os resultados referentes ao questionário semiestruturado.
} 


\footnotetext{
${ }^{3} \mathrm{O}$ texto-base, analisado pelos alunos, foi o videogame Dante's Inferno. Além desse, durante as aulas, foram apresentados trechos ou uma síntese da história de: Supernerd - a Saga Dantesca, de Laura Bergallo; O purgatório - a verdadeira história de Dante e Beatriz, de Mario Prata; A Divina Comédia em quadrinhos, de Piero e Giuseppe Bagnariol; e A Divina Comédia, de Dante Alighieri, em versão digital, incluindo informações sobre essas obras organizadas e dispostas em um modelo hipertextual, que o aluno pôde acessar no link <http://gameensino.dominiotemporario.com/home_0.html>, na escola ou fora dela, para continuar a aprender sobre Dante e A Divina Comédia e as obras citadas que dialogam com ela.
}

\section{Referências bibliográficas}

BRASIL. Secretaria de Educação Fundamental. Parâmetros Curriculares Nacionais: Ensino de primeira à quarta série: Língua Portuguesa. Brasília: MEC/SEF, 1997.

GEE, J. P. What video games have to teach us about learning and literacy. New York: PalGrave-McMillan, 2003.

HERSCHMANN, M. Repensando o sucesso dos videogames musicais na cultura contemporânea. Revista de Estudios para el Desarrollo Social de la Comunicación, v. 1, n. 6, 2012.

LOCATELli, P. Vale-Cultura para videogames. Carta Capital, 26 fev. 2013. Disponível em: <http://www.cartacapital.com.br/politica/vale-cultura-para-videogame s/>. Acesso em: 07 mar. 2013.

MARCUSCHI, L. A. Gêneros textuais: definição e funcionalidade. In: DIONÍSIO, A. P.; BEZERRA, M. A.; MACHADO, A. R. (Orgs.). Gêneros textuais e ensino. Rio de Janeiro: Lucerna, 2003, p. 20-36.

MENEGHELLI, A. Pratiche di gioco e significazione in atto. Ocula, Semiotica degli oggetti e delle interfacce. Saggi, 2005. Disponível em: <http://www.ocula.it/archivio/ txt/am_pratiche/meneghelli_pratiche.htm>. Acesso em: 30 mar. 2013.

Veja. São Paulo, edição 2238,12 out. 2011.

São Paulo, edição 2267, 02 maio 2012.

São Paulo, edição 2282, 15 ago. 2012.

Retratos da Leitura no Brasil. 3 ed. Instituto Pro-livro. 2011. Disponível em: <http://www.prolivro.org.br/ipl/publier4.0/dados/anexos/2834_10.pdf>. Acesso em: 08 jun. 2013.

SÁ, S. P.; ANDRADE, L. A. Second Life e Stars Wars Galaxies: encenando o jogo da vida na (ciber)cultura do entretenimento. In: Anais do XVII Encontro da Compós. São Paulo: UNIP, 2008.

SANTAELLA, L. Introdução. In: SANTAELLA, L.; FEITOSA, M. Mapa do Jogo: a diversidade cultural dos games. São Paulo: Cengage Learning, 2009.

ZAGAL, J. P. Ludoliteracy: defining, understanding, and supporting games education. ETC Press. Paper 4. 2010. Disponível em: 〈http://repository.cmu.edu/etc press/4〉. Acesso em: 11 mar. 2013. 